field experiments he has found that vaccinated cattle acquire a serviceable immunity. The policy now adopted by the Ministry of Agriculture is to use these two vaccines in infected herds in an attempt to reduce the immediate losses. From June 1 no animal in a TT (tuberculin tested) herd shall be vaccinated with live $B r$. abortus except with the approval of the Ministry of Agriculture, and only with an approved vaccine. Two approved vaccines are issued by the Ministry of Agriculture, No. 1 (standard) vaccine, which is prepared from the American, 'strain 19', and No. 2 vaccine, which is prepared from 'strain $45(20)$ '.

\section{Health Contrasts in the United States}

AN article in the March issue of the Statistical Bulletin, the organ of the Metropolitan Life Insurance Company of New York, discusses the difference in health in the United States during the War of 1914-18 compared with that in the present struggle, and comes to the conclusion that America is better prepared now for the hardships of modern warfare than twenty-five years ago. This is shown by the mortality among the industry policy holders of the Company, whose death-rate in the group 1-74 has been reduced slightly more than 50 per cent during the last quarter of a century. The diseases of childhood and infancy such as measles, whooping cough, scarlet fever, diphtheria, diarrhœa and enteritis have been virtually eliminated as causes of death during this period. There has been a considerable saving of life at this early age, and many young persons living to-day have been spared the disabling sequels of these diseases, so that thousands are now available for war service who would otherwise have been rejected. The death-rate from tuberculosis among the policy holders has been reduced by about one fifth. This is of great importance in connexion with the war effort, as many of the sufferers from tuberculosis are between the ages of twenty and fifty to which the great majority of the Fighting Forces belong. The mortality from syphilis, which occurs principally in youth and middle age and tends to increase in wartime, is less than half what it was in 1917. As regards influenza and pneumonia, which caused such heavy losses during 1914-18, the recent researches into the causal agent of the former are encouraging, while the latter, thanks to chemotherapy, has lost much of its terrors.

The increasing industrialization in the United States suggests that there may be an increase in fatal accidents in the near future, but the advance in industrial hygiene and prevention of accidents make it more likely that many lives and working days will be saved which under former conditions would have been lost. Improvement in pre-natal care, obstetric and hospital facilities is shown by the fact that whereas twenty-five years ago more than 17 out of every 100,000 policy holders died in childbirth, today this rate is reduced to 5 . The great increase in motor accidents since 1917 , due to the great increase in number of motor-vehicles, may possibly be mitigated by the curtailment of the supply of rubber and petrol.

\section{Health of the United States Army}

According to the annual report of the SurgeonGeneral of the U.S. Army, summarized in the Journal of the American Medical Association of April 18, 257,136 men were reported sick from all causes in
1940, giving an annual rate per thousand of $763 \cdot 3$, an increase of 44 per cent over that of 1939 , which was the lowest on record. The largest number of admissions was due to respiratory diseases. Then came infectious diseases and diseases of the digestive system. There were 267 admissions with 108 deaths due to aircraft accidents in 1940, and 32 deaths from accidental drowning. The admission for venereal diseases was 42.5 per thousand, and the number of days lost due to this cause 456,148 . The average number of men absent from duty each day for venereal disease was 1,246 and the average length of treatment was 52 days. The average number of days lost for syphilis was 28, for gonorrhoea 35 and for other venereal diseases 20. During the year, 1.39 per cent of the strength of the army was lost by discharge or retirement for physical disability. Dementia præcox was the chief cause for discharge. Tuberculosis reached a new low level. There were 229 deaths attributed to motor accidents.

\section{Electrically Driven Excavators}

Is a paper given before the Institution of Electrical Engineers on May 14, P. H. R. Durand points out that the electrically equipped single-bucket excavator is employed extensively in the quarrying of rocks such as limestone and chalk for cement manufacture, ironstone and other minerals and also for excavating granite, sand and gravel, clays and shales. Large installations are used in the open-cast mining of coal. These machines are also used sometimes around industrial works for handling materials such as blast-furnace slag. In some quarries the excavator provides raw material which is processed in an adjoining factory and for which there may be limited accommodation prior to processing. The excavator is here the starting-point of a mass-production unit, its rate of output being measured by the hour instead of by the week or month, and in applications of this type it must be regarded as an automatic machine. The author describes the sphere of application of the excavators and, in commenting on the increasing importance of electric drive, gives an explanation of the fundamental motions and structural limitations of the machines.

A summary of the special service conditions precedes a discussion on electric drive methods for the two main groups of excavators, the 'friction' type and the individual-drive machine, where the application of the modern Ward-Leonard system with 3 -coil dynamo and separately excited motor is referred to in some detail. Main and auxiliary equipment is described from the electrical and mechanical aspects, and installation and wiring details are supplemented by illustrations of typical equipment layouts and wiring diagrams. Attention is directed to certain special aspects of power supply and distribution to excavating projects, representative power consumptions being given. The scope of the paper is limited by present circumstances, no reference being made to Continental or overseas practice, or to the dipper dredge, which, possessing an operating cycle similar to that of shovel excavators, is equipped with motors and control of equivalent characteristics. Illustrations are confined to the smaller machines, since up to the present time the scope of excavating operations in Great Britain has not stimulated any demand for the larger machines except for stripping shovels to remove deep overburden in the ironstone mines. 